\title{
A novel rocket-borne ion mass spectrometer with large mass range: instrument description and first-flight results
}

\author{
Joan Stude ${ }^{2}$, Heinfried Aufmhoff ${ }^{2}$, Hans Schlager ${ }^{2}$, Markus Rapp $^{2,1}$, Frank Arnold ${ }^{4,2}$, and Boris Strelnikov ${ }^{3}$ \\ ${ }^{1}$ Atmospheric Physics, Ludwig-Maximilians-Universität München (LMU), Munich, Germany \\ ${ }^{2}$ German Aerospace Center (DLR), Institute of Atmospheric Physics, Oberpfaffenhofen, Germany \\ ${ }^{3}$ Leibniz-Institute of Atmospheric Physics (IAP), Kühlungsborn, Germany \\ ${ }^{4}$ Max Planck Institute for Nuclear Physics (MPIK), Heidelberg, Germany
}

Correspondence: Joan Stude (joan.stude@ dlr.de)

Received: 22 May 2020 - Discussion started: 24 June 2020

Revised: 19 November 2020 - Accepted: 28 November 2020 - Published: 9 February 2021

\begin{abstract}
We present a novel rocket-borne ion mass spectrometer named ROMARA (ROcket-borne MAss spectrometer for Research in the Atmosphere) for measuring atmospheric positive and negative ions (atomic, molecular and cluster ions) and positively and negatively charged meteor smoke particles. Our ROMARA instrument has, compared to previous rocket-borne ion mass spectrometers, a markedly larger mass range of up to $m / z 2000$ and a larger sensitivity, particularly for meteor smoke particle detection. The major objectives of this first ROMARA flight included the following: a functional test of the ROMARA instrument, measurements between 55 and $121 \mathrm{~km}$ in the mass range of atmospheric positive and negative ions, a first attempt to conduct mass spectrometric measurements in the mass range of meteor smoke particles with mass-to-charge ratios up to $m / z 2000$, and measurements inside a polar mesospheric winter echo layer as detected by ground-based radar. Our ROMARA measurements took place on the Arctic island of Andøya, Norway, at around noon in April 2018 and represented an integral part of the polar mesospheric winter radar echo (PMWE) rocket campaign. During the rocket flight, ROMARA was operated in a measurement mode, offering maximum sensitivity and the ability to qualitatively detect total ion signatures even beyond its mass-resolving mass range. On this first ROMARA flight we were able to meet all of our objectives. We detected atmospheric species including positive atomic, molecular and cluster ions along with negative molecular ions up to about $m / z$ 100. Above $m / z$ 2000, ROMARA measured strong negative-ion signatures, which are likely due to negatively charged meteor smoke particles.
\end{abstract}

\section{Introduction}

Meteor smoke particles (MSPs) are of considerable current interest since they have several interesting atmospheric roles. MSPs may act as sites of heterogeneous reactions involving atmospheric trace gases and ions. Moreover, MSPs act as nuclei in the formation of mesospheric water ice clouds (Rapp and Thomas, 2006) and as nuclei in the formation of the stratospheric sulfuric acid (Arnold and Fabian, 1980; Arnold et al., 1981; Hervig et al., 2017) and nitric acid aerosol layers (Arnold and Knop, 1989; Arnold et al., 1989; Voigt et al., 2005; Frankland et al., 2015; James et al., 2018; Curtius et al., 2005), which have an impact on ozone and climate (Crutzen and Arnold, 1986). MSPs may also influence the charge balance of the lower ionosphere by acting as scavengers of free electrons and ions (Schulte and Arnold, 1992; Rapp and Lübken, 2001; Friedrich et al., 2012). Furthermore, electrically charged MSPs have been proposed to play a potential role in the formation of polar mesospheric winter radar echoes (PMWEs) (Rapp et al., 2011; La Hoz and Havnes, 2008).

MSPs are formed by the ablation of meteors or interplanetary dust particles in the upper atmosphere, as was originally hypothesized by Rosinski and Snow (1961). The ablation process causes meteoric vapours to be released, mostly at altitudes around $90 \mathrm{~km}$ in the mesopause region, during entry into the atmosphere at high velocities (Kalashnikova et al., 2000; Plane, 2003). Hereafter, such vapours undergo gas phase reactions with atmospheric gases and ions and ultimately recondense, leading to tiny aerosol particles (Plane, 


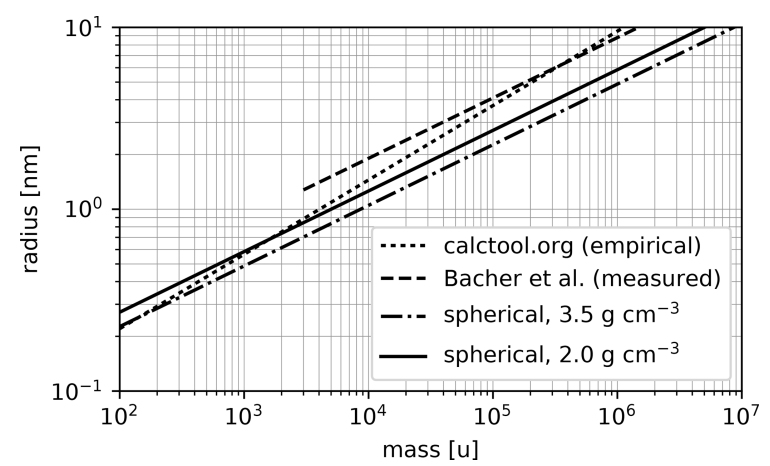

Figure 1. Comparison of different relationships between molecule mass and size with data from Bacher et al. (2001) and Shipway and Shipway (2008).

2012). Hunten et al. (1980) termed these particles meteor smoke particles and conducted model simulations predicting an MSP layer to be present between 70 and at least $100 \mathrm{~km}$, peaking at around $85 \mathrm{~km}$. The predicted MSP radii range is from 0.2 to $10 \mathrm{~nm}$, corresponding to hundreds to millions of atomic mass units (u) (Fig. 1). For example, at $85 \mathrm{~km}$, MSPs with radii larger than $0.2 \mathrm{~nm}$ have a predicted number concentration of $7 \times 10^{4} \mathrm{~cm}^{-3}$. The meteor vapours, which lead to MSP formation, are to a large part composed of metal and silicon atoms formed mostly via ion-molecule reactions with atmospheric positive ions. Early rocket-borne ion composition measurements of the whole suite of the most abundant meteoric positive-ion species ( $\mathrm{Fe}, \mathrm{Mg}$ and $\mathrm{Si}$ ) and their isotopes revealed an ion composition similar to the elemental composition of chondrites (Krankowsky et al., 1972). The mass density of ordinary chondrites is about $3.5 \mathrm{~g} \mathrm{~cm}^{-3}$ (Britt and Consolmagno, 2003); however, the ablation process might form particles with lower densities of $2.0 \mathrm{~g} \mathrm{~cm}^{-3}$, as assumed by Hunten et al. (1980) and Plane et al. (2014).

Using the above values in Fig. 1 and assuming a spherical MSP particle of $0.3 \mathrm{~nm}$ radius, one would estimate an effective mass of about 135 to $240 \mathrm{u}$. The first observational indications for the presence of such negatively charged nascent MSPs ( $>473 \mathrm{u}$ ) have been obtained from rocket-borne measurements of ion mass spectrometers by Schulte and Arnold (1992) under twilight conditions. Meanwhile several rocketborne electrostatic probe measurements provided evidence for larger MSPs than measured by the ion mass spectrometers (Gelinas et al., 1998; Rapp et al., 2005; Lynch et al., 2005; Strelnikov et al., 2012; Robertson et al., 2014; Havnes et al., 2015; Asmus et al., 2017). Even some of the first direct information on the chemical nature of MSPs was obtained by rocket-borne photoionization measurements. It was found that the ionization potential of MSPs is somewhat similar to that of $\mathrm{Fe}$ and $\mathrm{Mg}$ hydroxide clusters (Rapp et al., 2012). Besides those direct in situ measurements, more indirect measurements of MSP signatures in the spectra of incoherent scatter radars were reported by several investigators
(Rapp et al., 2007; Strelnikova et al., 2007; Fentzke et al., 2009, 2012). Also, satellite measurements with the Solar Occultation For Ice Experiment (SOFIE) have provided clear evidence of MSPs in solar occultation extinction measurements (Hervig et al., 2009).

The present paper reports on the search for MSPs using a novel rocket-borne ion mass spectrometer having an increased mass range of up to $m / z 2000$ and an increased sensitivity. Importantly, the rocket flight was determined to penetrate a PMWE layer, which which was indeed accomplished. Details about the PMWE campaign will be given in Strelnikov et al. (2021) and Staszak et al. (2021). Here we give a thorough description of the ROMARA instrument and a brief presentation of the ion and MSP data.

\section{Instrument description}

The ROMARA instrument is a cryogenically pumped quadrupole mass spectrometer based on earlier designs from the Max Planck Institute for Nuclear Physics (MPIK) (Arnold et al., 1971; Krankowsky et al., 1972; Arnold et al., 1977b). Cross sections of the instrument and mass spectrometer are shown in Fig. 2. Ions enter the instrument through a knife edge intake orifice with a radius of $0.5 \mathrm{~mm}$ on the tip of a double cone. The design allows one to sample the atmosphere in front of the shock due to the supersonic speed of the payload. A quadrupole lens (Brubaker, 1968) $36 \mathrm{~mm}$ in length is mounted between the intake orifice and quadrupole, with skewed tips for a placement as close as possible to the intake cone. The quadrupole mass filter has a length of $115 \mathrm{~mm}$ and uses cylindrical rods $2.4 \mathrm{~mm}$ in radius. The field radius $r_{0}$ between the rods is given by a ratio of $r_{\text {rod }} / r_{0}=$ 1.128 , as recommended by Douglas (2009).

Ions passing the mass filter are detected by a channel electron multiplier (CEM) placed in the centre of the instrument in the line of sight of the intake orifice. The quadrupole and detector are almost completely surrounded by the cryopump, which also serves as a mechanical support. A cap seals the instrument intake during storage and launch and is jettisoned before the measurements begin. For this purpose, a spring loaded bayonet ring is turned by pyro-actuators to release the cap. Inside the cap, a commercial ion source (electron ionization, Hiden Analytical 205011) allows one to calibrate and test the instrument on the ground and monitor operation during launch until the cap together with the ion source is removed. To increase ion transmission, independent bias potentials can be applied to the intake cone, quadrupole lens and rods (see Sect. 2.4). To maximize detection efficiency, especially for heavy ions, the CEM (Photonis $4830-\mathrm{MgO}$ ) is coated with magnesium oxide and biased to $\pm 1800 \mathrm{~V}$ with a constant voltage across the CEM of about $+2700 \mathrm{~V}$. Measuring positive ions requires all bias voltages to be negative and vice versa. For an alternating operation of the instru- 


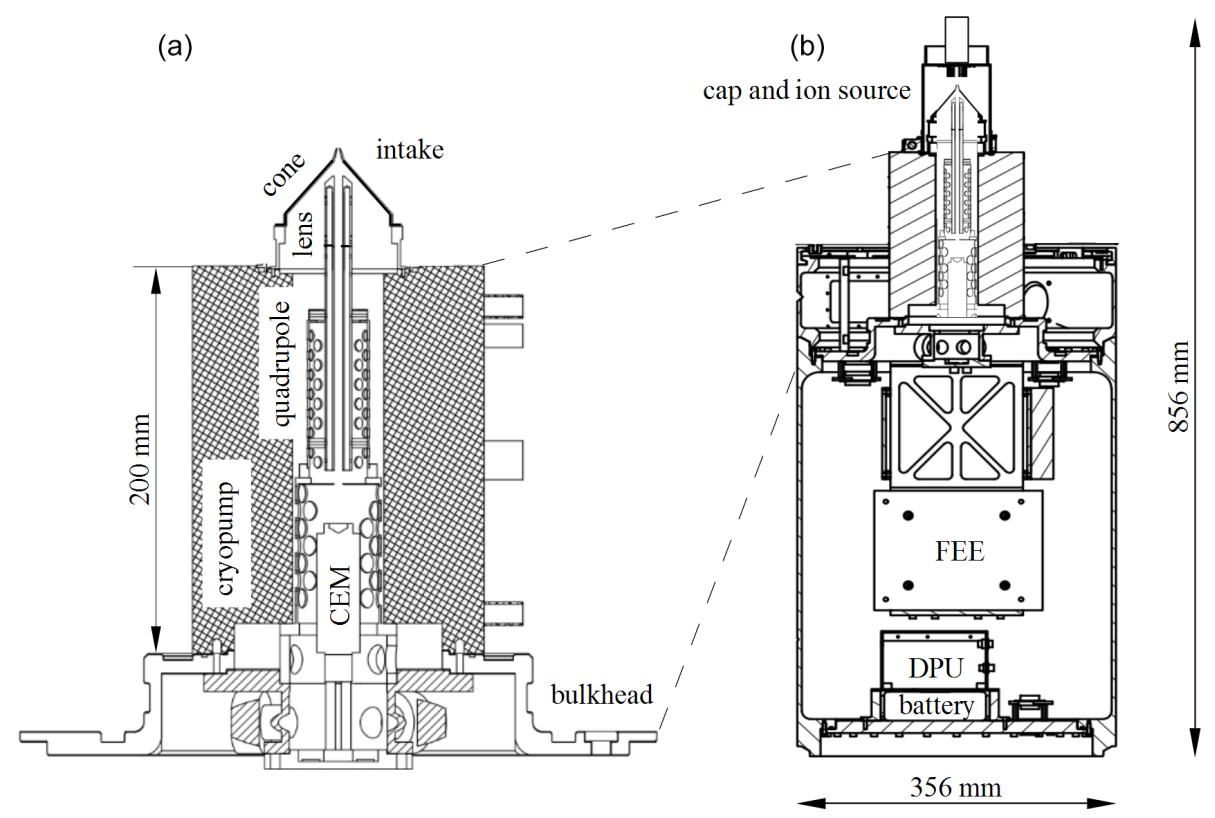

Figure 2. (a) Detailed cross section of the ROMARA mass spectrometer in flight configuration. (b) Cross section of the complete ROMARA instrument in launch configuration. CEM: channel electron multiplier; FEE: front-end electronics; DPU: data processing unit.

ment between positive and negative ions, the bias voltages are switched in the dead time between the spectra.

The cryopump is a bath-type design using gold-plated cooling surfaces. A heat shield, cooled by the evaporating cryogen, is placed between the reservoir and outer shell. Liquid helium is most readily available cryogen; however, it evaporates rather quickly and the reservoir would be depleted in about $1 \mathrm{~h}$. Longer standby times can be achieved using neon because of its higher vaporization enthalpy. Thus, the rocket can be safely prepared for launch and the probability of meeting the desired atmospheric conditions during a day of work is higher. On the day of launch, a total standby time of $\approx 7 \mathrm{~h}$ with subsequent successful operation was achieved. We produced liquid neon at the launch site by liquefying neon gas with liquid helium. A disadvantage of using neon as the cryogen is the inefficient pumping of hydrogen, helium and neon itself due to their boiling points being below or at that of neon. While parts of these gases are trapped in the frozen air building up on the cooling surfaces, the remaining gas (mostly helium) could accumulate above a critical pressure. However, for our combination of intake size and duration of flight this is not of concern.

A reinforced bulkhead holds the complete construction of electronics, quadrupole and cryopump. The bulkhead further seals the main structure against the atmosphere and water during splashdown. The front-end electronics (FEEs), dataprocessing unit (DPU) and batteries are housed in the main structure at 1.5 bar absolute nitrogen pressure to safely handle high voltages. The whole instrument is $856 \mathrm{~mm}$ in length with a diameter of $356 \mathrm{~mm}$ and a total mass of about $50 \mathrm{~kg}$.

\subsection{Principle of operation}

A quadrupole mass spectrometer separates ions by their mass-to-charge ratio $(\mathrm{m} / \mathrm{z})$ by applying electrical fields along a central drift path of ions. These fields are ideally hyperbolic but are often approximated by cylindrical electrodes, the rods, circularly arranged along their length. The required fields are formed by radio frequency (VRF) and static (VDC) potentials with opposite polarity at neighbouring rods. Thus, opposing rods are electrically connected and form two pairs of rods. Ions of a certain $m / z$ retain stable trajectories, pass the quadrupole and can be detected at the exit, while other ions collide with the rods and are lost. To pull ions in between the rods, a constant bias voltage $V_{\mathrm{B}}$ is applied to all rods, i.e.

$V_{\mathrm{rod}}=V_{\mathrm{B}} \pm\left[V_{\mathrm{DC}}+V_{\mathrm{RF}} \cos (\omega t)\right]$.

The quadrupole allows two modes of operation: an RF-only mode and a line mode. In RF-only mode, VDC is set to zero. With increasing VRF, lower masses are rejected until a maximum VRF is reached. The count rate in the detector will thus eventually drop for each ion mass and produce a step in the recorded mass spectrum, which can be analysed for width and height. Ions with masses above the mass given by the maximum VRF still pass the quadrupole but can not be mass analysed. This is often described as a highpass mass filter, although it is actually a wide bandpass, as illustrated in Fig. 3. We simulated transmission curves for different mass settings of the quadrupole and different ion masses using SIMION ${ }^{\circledR}$ (Dahl, 2000) to model the electrical fields and individual ion trajectories. Collisions with the 


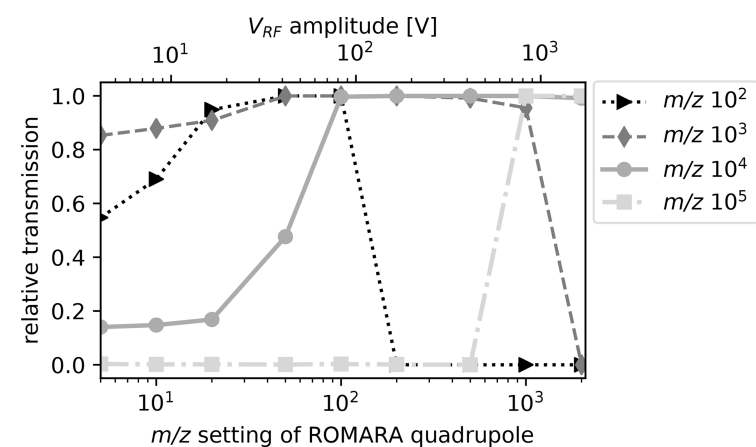

Figure 3. SIMION $^{\circledR}$ simulation of ROMARA quadrupole for heavy-ion transmission in RF-only mode for an angle of attack of $2.2^{\circ}$.

background gas or charge exchange processes were omitted. For each ion mass per charge and mass per charge setting of the quadrupole, a population of 3000 ions is started inside the intake orifice with a constant velocity of $980 \mathrm{~m} \mathrm{~s}^{-1}$ (i.e. rocket velocity, $v$ ), an angle of attack of $2.2^{\circ}$ and a uniform conical direction distribution with an opening angle $\delta$ defined as

$\delta=2 \operatorname{atan}\left(\frac{3 k T}{m v}\right)$,

where $k$ is the Boltzmann constant, $T$ is temperature $(180 \mathrm{~K})$ and $m$ is ion mass.

It is evident that for low VRF values, and hence mass settings of the quadrupole, only small fractions of ions above $10^{4} \mathrm{u}(\approx 1.2 \mathrm{~nm}$ radius) pass the quadrupole to the detector. Ions with sufficient masses and thereby sufficient kinetic energy do not respond efficiently to the small applied fields. In this case the intake orifice and exit aperture act as collimator and limit the detector flux to trajectories smaller than $0.85^{\circ}$ from the central axis. The instrument thus mass analyses particles up to $m / z 2000$ and detects the presence of particles up to about $m / z 3 \times 10^{5}$ ( $\approx 3 \mathrm{~nm}$ radius). For the line mode with an additionally applied VDC, this effect is much smaller and can be neglected. For the quadrupole to operate in line mode, the VDC is set to a constant ratio to VRF and thus forms a narrow band pass mass filter. With increasing voltages, the band pass window is moved from low to high masses and a line spectrum can be recorded. The ratio of VDC to VRF determines the size of the band pass window and thus resolution and sensitivity. The voltage applied to the quadrupole lens always corresponds to VRF only. This minimizes ion losses at the entrance to the rod system when the quadrupole is operated in line mode.

\subsection{Ion sampling from the atmosphere}

The payload moves at supersonic speeds through the atmosphere, developing a shock in the ram direction. The knife edge double cone is designed to sample ions in front of

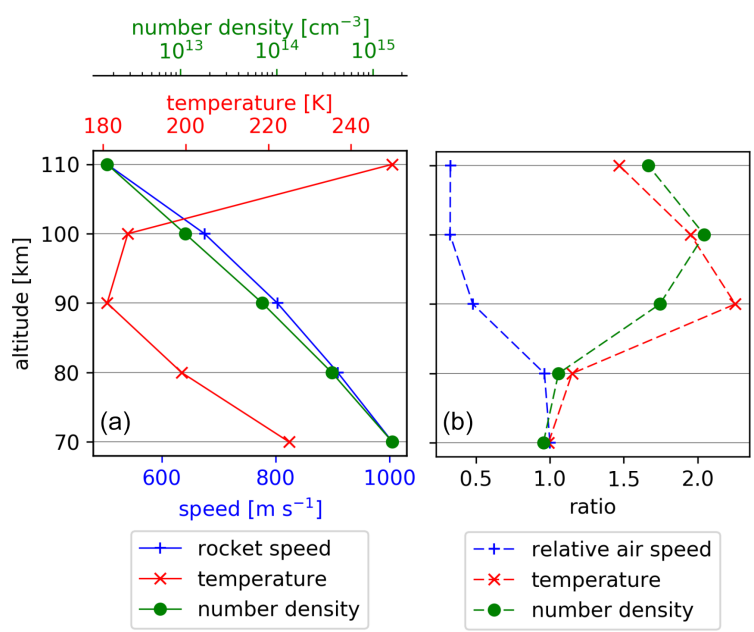

Figure 4. (a) DS2V simulation input parameters from the NRLMSISE-00 Atmosphere Model. (b) DS2V simulation results $1 \mathrm{~cm}$ upstream of the inlet orifice plotted as a ratio to ambient values of relative air speed, atmospheric temperature and number density.

the shock, avoiding perturbations and possible breakup of weakly bound ions. The shock was simulated with the direct Monte Carlo simulation software DS2V (Bird, 1988, 1994) under conditions of a standard atmosphere with a composition of nitrogen and oxygen (NRLMSISE-00) and rocket speeds appropriate for our flight. Figure 4a shows the rocket speed, temperature and number density for different altitudes used in the simulation. Figure $4 \mathrm{~b}$ shows the relative air speed and the increase of temperature and number density $1 \mathrm{~cm}$ upstream from the intake orifice. Up to $80 \mathrm{~km}$ the ratios stay at about unity. Above $80 \mathrm{~km}$ the shock starts to detach from the payload and the number density and temperature begin to increase while the relative air speed decreases. Values change roughly by a factor of 2 at $100 \mathrm{~km}$ altitude as compared to undisturbed conditions. Particles with much larger masses, such as MSPs, will be less affected by the shock formed by air molecules (Hedin et al., 2007; Asmus et al., 2017) and thus penetrate it more efficiently.

\subsection{Electronics}

As front-end electronics we use modified electronics from the MPIK originally developed for aircraft operations, e.g. the quadrupole power supply. The electronic pulses from the CEM are transformed by an Amptek A111F charge amplifier to digitally countable pulses. To control the frontend electronics and process the data we use a microprocessor/FPGA system from National Instruments (sbRIO-9637). During ground preparation the system can be remotely controlled and updated if necessary. After launch, the system is controlled by a timeline programme that does not allow further interactions. The data are transmitted via the rocket service module but are also stored on an internal SD card. The data volume is about $10 \mathrm{kB}$ per spectrum. The instru- 
ment is self-powered using lithium iron phosphate batteries, which allow approximately $1.5 \mathrm{~h}$ of operation. A mass spectrum is divided into 4096 mass channels with a dwell time of $300 \mu \mathrm{s}$. This results in a total time of $1.274 \mathrm{~s}$, including $0.045 \mathrm{~s}$ of dead time at the beginning of each spectrum. The total time of a spectrum, and thus height resolution during flight, is mostly limited by the VRF oscillator. The oscillator runs at about $1.4 \mathrm{MHz}$ with a maximum amplitude (VRF) of $\approx 1750 \mathrm{~V}$

\subsection{Calibration}

The bias voltages of the quadrupole lens and the rods were calibrated using positive xenon ions. The intake cone potential was set to zero and therefore to the payload's ground. We found an optimum transmission if the rods and quadrupole lens have potentials of $-50 \mathrm{~V}$ and $-20.5 \mathrm{~V}$ respectively. For negative ions the same absolute values were used. During tests we observed a significant loss of transmission if both voltages were equal. For the mass calibration of the instrument we used $4 \mathrm{eV}$ ions of neon, krypton, xenon and perfluorotributylamine (PFTBA, Heptacosa, FC-43), allowing a calibration up to $m / z$ 502. In Fig. 5a we show measurements of $\mathrm{Kr}$ and $\mathrm{Xe}$ ions, the cumulative distribution function (CDF) fits of the ion mass steps, the reconstructed Gaussian peaks and the respective isotope lines from the National Institute of Standards and Technology (NIST). The mass resolution $m / \Delta m$ at $50 \%$ peak height was determined to be about 17.5 $(\approx 5 \mathrm{u}$ peak width for $\mathrm{Kr})$ and the theoretical mass range from $m / z 5$ to $m / z$ 2075. In the lower panel we show the standard spectrum of PFTBA from NIST data and the measured spectrum from ROMARA. The NIST spectrum was converted to an RF-only version by summing up all single peaks in the NIST data. The measured ROMARA spectrum was normalized to the $m / z 69$ peak and shows good agreement for the major steps of PFTBA up to $m / z$ 502. Steeper falloffs between the major PFTBA steps are a result of typical hydrocarbon contaminations of the ion source (steps $<m / z 300$, Fig. 6a). In cases where there are many small peaks close to each other, the ROMARA spectrum turns into a continuous slope because of the limited mass resolution.

The noise level of the instrument is mostly determined by the oscillator and the switching between positive- and negative-ion mode leading to increased counts at the beginning and end of each spectrum, especially in the negativeion mode. On the launch pad with the instrument operating nominally and the ion source switched off, the average noise floor over a whole spectrum was $9 \mathrm{~Hz}$ in positive-ion mode and $240 \mathrm{~Hz}$ in negative-ion mode, well below our one-count limit of $3.3 \mathrm{kHz}$.
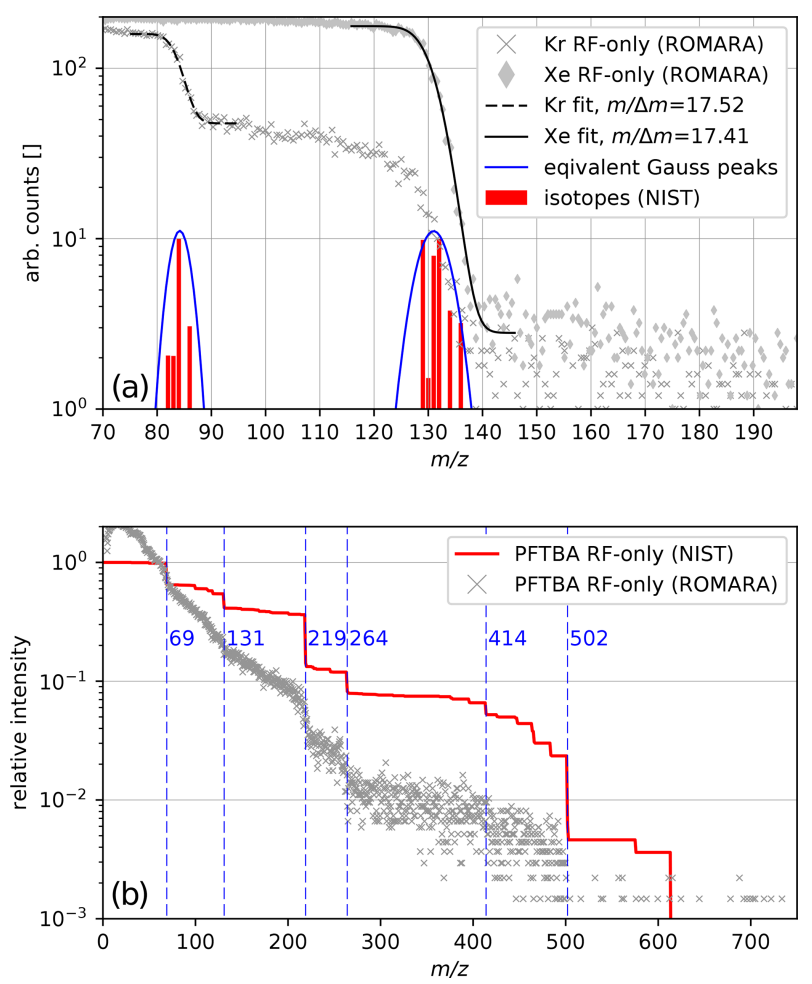

Figure 5. (a) RF-only spectrum of $\mathrm{Kr}$ and $\mathrm{Xe}, \mathrm{CDF}$ fits and equivalent Gauss peaks. (b) ROMARA RF-only measurement of PFTBA and NIST data of PFTBA.

\section{Measurement and discussion}

\subsection{Launch conditions}

The main launch criteria were determined by the MAARSY radar (Latteck et al., 2012; Rapp et al., 2011; Latteck et al., 2019), looking for polar mesospheric winter echoes. The radar pointed alternately along the rocket trajectory and to the zenith (see Latteck et al., 2019, for details). In the days before launch, several echoes were detected but other launch criteria, e.g. for the sea recovery, were not met. On 13 April 2018 at 09:44:00 UTC, ROMARA was launched directly into an echo between 78 and $80 \mathrm{~km}$ altitude, with weaker echoes visible just before at around 65 and $70 \mathrm{~km}$. After separating the nose cone at $52.2 \mathrm{~km}$, the instrument cap was jettisoned at $54.5 \mathrm{~km}$ and the ROMARA measurements began. At $60.0 \mathrm{~km}$ the motor was separated from the payload. The payload hit the echo at its decaying tail before reaching an apogee of $121.4 \mathrm{~km}$. The electron density was measured with the on-board wave propagation experiment (Friedrich et al., 2013) but also with the Saura MF radar (Latteck et al., 2019) about $20 \mathrm{~km}$ south of the launch site. The ionosphere was moderately disturbed with a simulated riometer absorption of $0.26 \mathrm{~dB}$ at $27.6 \mathrm{MHz}$. At the given time and location, a solar zenith angle of $61.6^{\circ}$ is calculated; the direction of the launch was $330^{\circ}$ azimuth (northwest by north). 

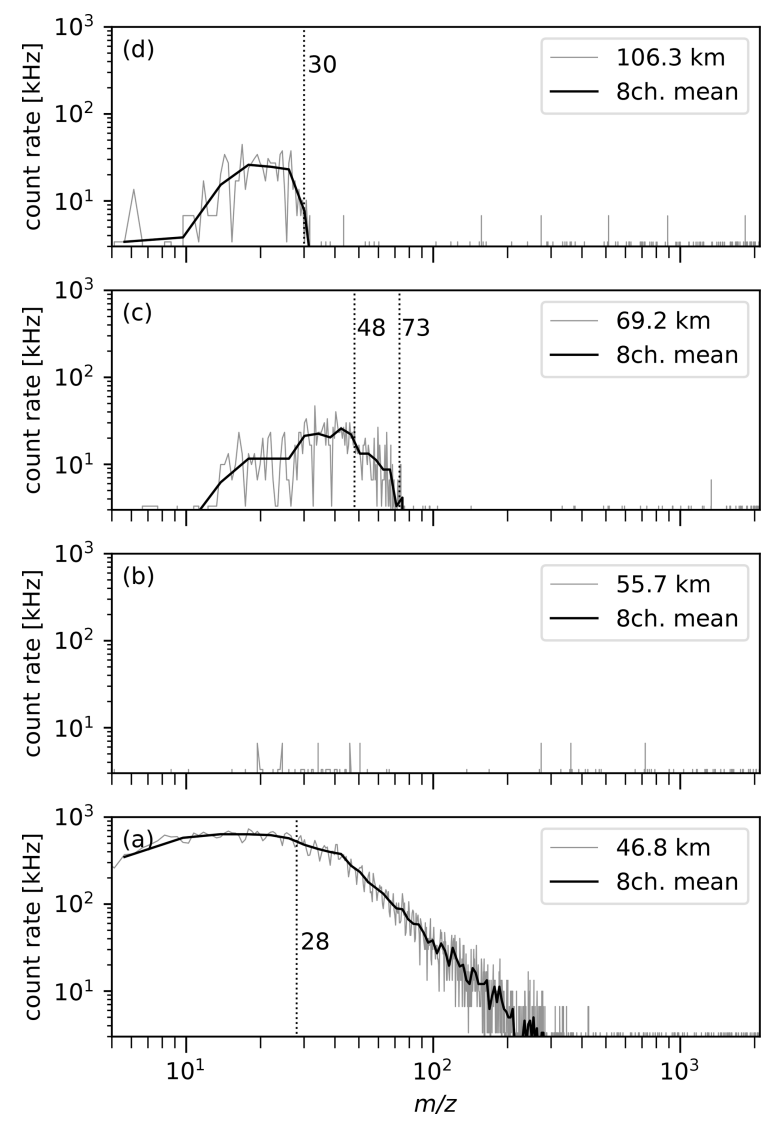

Figure 6. Positive-ion mass spectra at four different altitudes during ascent in logarithmic scales. Spectrum (a) shows the residual gas spectrum from the internal ion source before ejecting the cap. Spectrum (b), (c) and (d) show natural ambient ions. The vertical resolution for spectrum (b), (c) and (d) is 1426, 1270 and $678 \mathrm{~m}$ respectively.

\subsection{Ion measurements}

The instrument was operated in RF-only mode throughout the flight and measured natural ions during the ascent from 54.5 to the apogee at $121.4 \mathrm{~km}$ but also on the downleg in the rocket wake. The intake cone was applied with a constant $0 \mathrm{~V}$ bias and thus was at payload potential during the whole flight. In this instrumentally oriented paper, we present eight exemplary mass spectra, obtained during rocket ascent: four positive and four negative. These include two test spectra obtained just prior to cap ejection and six ambient ion spectra. A more detailed analysis of the ion measurements will be presented elsewhere. The internal ion source was operated up to $49 \mathrm{~km}$ altitude and was switched off before the ejection of the cap. Other spectra were chosen around 70 and $106 \mathrm{~km}$. At $70 \mathrm{~km}$ the sampling conditions are ideal with the shock wave being well attached to the intake cone as the simulations of Fig. 4 show. Thus, ions enter the instrument with minimum disturbance and under small angles of attack $\left(\alpha \approx 2.2^{\circ}\right)$. In contrast to $70 \mathrm{~km}$, the spectrum at $106 \mathrm{~km}$ is much more af- fected by the shock; it is now completely detached and the angles of attack are considerably larger $\left(\alpha \approx 11.4^{\circ}\right)$.

Raw count rates $c_{\text {raw }}$ were corrected for detector dead time $\tau$ and angle of attack $\alpha$. The angle was provided by the rocket operator, and the dead time was taken from the A111F data sheet with $\tau=350 \mathrm{~ns}$, giving the corrected count rate $c$ :

$c=\frac{c_{\text {raw }}}{\left(1-c_{\text {raw }} \tau\right) \cdot \cos (\alpha)}$.

In Figs. 6 and 7 we included an eight-channel mean, as the original data are noisy. The count rates given hereafter refer to the eight-channel running mean count rate.

\subsection{Positive ions}

Figure $6 \mathrm{a}$ depicts a positive test spectrum obtained at $46.8 \mathrm{~km}$, prior to cap ejection, with the internal ion source in operation. In contrast to the calibration data of Fig. 5, where a laboratory power supply for the ion source is used, the internal power supply provides a less stable current and typical residual gas steps are not clearly visible. However, the count rate clearly decreases from about $m / z 28$ up to $m / z$ 300, typical for leaking air and contamination, e.g. hydrocarbons, in the ion source and cap. The maximum count rate is $636 \mathrm{kHz}$ for below $m / z 28$.

Figure $6 \mathrm{~b}$ depicts the spectrum at $55.7 \mathrm{~km}$, just after ejecting the cap, and serves to show that no residuals are present in the mass spectrum. Some counts of the same type as in the spectrum of Fig. $6 \mathrm{c}$ are already visible.

Figure 6c depicts a spectrum starting at $69.2 \mathrm{~km}$ altitude with ambient atmospheric positive ions. It has a maximum mean count rate of about $26 \mathrm{kHz}$ and a maximum of $m / z 76$, which is most likely due to the expected proton hydrate $\mathrm{H}^{+}\left(\mathrm{H}_{2} \mathrm{O}\right)_{4}[73 \mathrm{u}]$. This proton hydrate of fourth order has been measured previously (Arnold et al., 1977a; Kopp et al., 1984) often together with $\mathrm{H}^{+}\left(\mathrm{H}_{2} \mathrm{O}\right)_{3}[55 \mathrm{u}]$ and higher orders. However, in this particular spectrum, a step is found at around $m / z 49$, which is thus more likely due to $\mathrm{NO}^{+}\left(\mathrm{H}_{2} \mathrm{O}\right)[48 \mathrm{u}]$. A less defined step around $m / z$ 58, with only few counts per mass channel, likely corresponds to $\mathrm{H}^{+}\left(\mathrm{H}_{2} \mathrm{O}\right)_{3}[55 \mathrm{u}]$.

In Fig. 6d a spectrum at $106.3 \mathrm{~km}$ is shown with a similar maximum count rate of $26 \mathrm{kHz}$ with a step around $\mathrm{m} / \mathrm{z} 28$. This is consistent with $\mathrm{NO}^{+}[30 \mathrm{u}]$ or $\mathrm{O}_{2}^{+}[32 \mathrm{u}]$ as the most dominant ions at that altitude.

It is noticeable that the spectra do not start at maximum count rates. This is qualitatively the same effect as shown by the $100 \mathrm{u}$ curve in Fig. 3.

None of these positive-ion spectra indicate the presence of heavy positive ions.

\subsection{Negative ions}

In Fig. 7 we show characteristic negative-ion spectra for altitudes similar to those in Fig. 6. The spectrum in Fig. 7a 

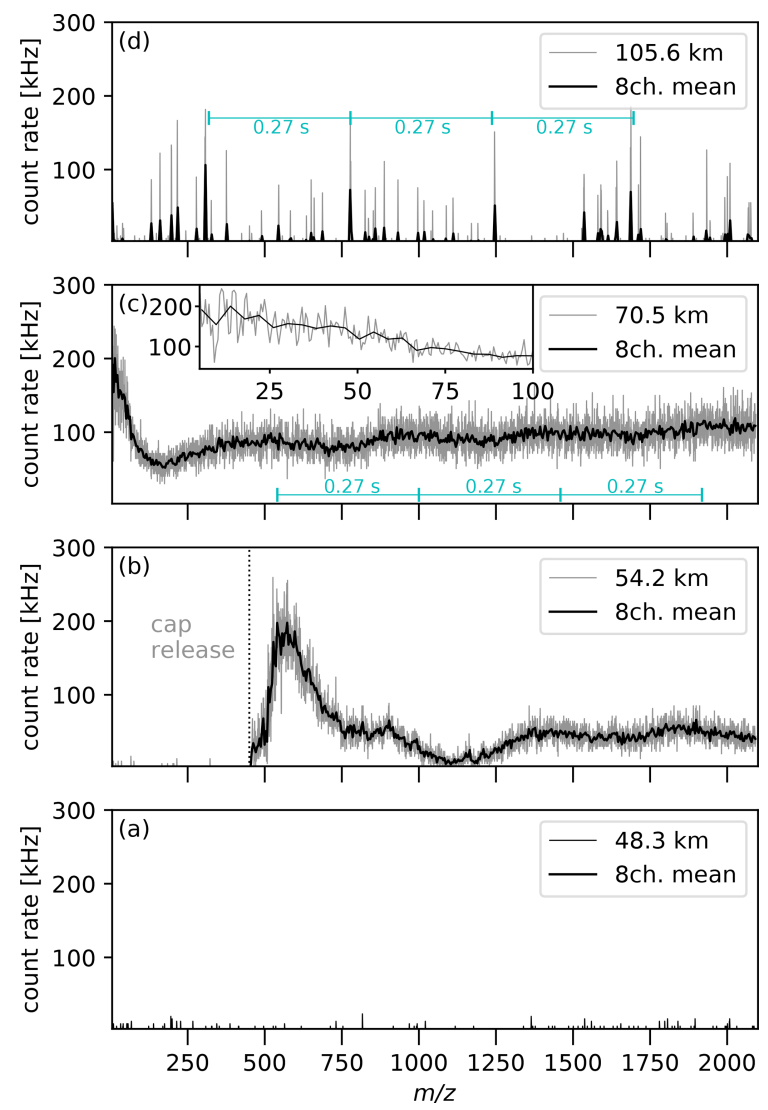

Figure 7. Negative-ion mass spectra in linear scales during ascent, at similar altitudes as the positive-ion mass spectra. In spectrum (a) the instrument is still sealed to the environment, while in spectra (b), (c) and (d) natural ambient ions are present. The vertical resolution for spectrum (b), (c) and (d) is 1431, 1245 and $688 \mathrm{~m}$ respectively.

is taken before cap ejection at an altitude of $48.3 \mathrm{~km}$ with the ion source operating. As expected, negative ions are not present, as they are not formed by the ion source (electron ionization) in the cap.

Figure $7 \mathrm{~b}$ shows the spectrum beginning at $54.2 \mathrm{~km}$ altitude, in which the cap was ejected. Before cap ejection the count rate is at the same low noise level as in Fig. 7a. Instantaneously, with cap ejection around $m / z$ 400, the count rate increases to a plateau around $\mathrm{m} / z 560$ with a maximum count rate at $200 \mathrm{kHz}$. Hereafter, the count rate decreases to about $50 \mathrm{kHz}$ showing some minima and maxima, possibly related to rocket spin. Towards the end of the spectrum the count rate remains at about $50 \mathrm{kHz}$ indicating ions beyond our mass range of $m / z 2000$.

Figure $7 \mathrm{c}$ at $70.5 \mathrm{~km}$ altitude contains light negative ions with a maximum count rate of $200 \mathrm{kHz}$, exceeding the positive count rate almost 10 -fold. The count rate at the end of the spectrum is about $100 \mathrm{kHz}$. The inset is a blow-up of the small-ion mass range to $m / z 100$, indicating the presence of numerous unresolved mass steps with high count rates even at the smallest mass channels. Potential mass steps can be found around $m / z$ 24, $m / z$ 48, $m / z 58, m / z 65$ and $m / z 79$. These steps could be caused by $\mathrm{CN}^{-}[26 \mathrm{u}], \mathrm{C1}^{-}\left(\mathrm{H}_{2} \mathrm{O}\right)[53 \mathrm{u}]$, $\mathrm{CO}_{3}^{-}[60 \mathrm{u}], \mathrm{HCO}_{3}^{-}[61 \mathrm{u}], \mathrm{NO}_{3}^{-}[62 \mathrm{u}]$ and $\mathrm{CO}_{4}^{-}[76 \mathrm{u}]$, some of which have been previously measured by Arnold et al. (1971, 1982) and Kopp (1992). The heavy-ion signature is now clearly modulated by the rocket spin $(3.6 \mathrm{~Hz})$ with the maxima being about $0.27 \mathrm{~s}$ apart and thus requiring 4.5 modulations of the incident ion flux within a full spectrum. This can only be caused by asymmetries in the ion optics or at the intake orifice under angles of attack larger than zero. We therefore interpret this signal as negative ions with masses above our mass range of $m / z$ 2000. Other origins of this signal, such as stray UV light, neutral particles or a pressure effect inside the instrument, can most likely be ruled out. While UV light or neutral particles could trigger false counts, this would also be visible in the positive-ion mode and was tested for UV light in the laboratory. A pressure effect inside the instrument due to the higher voltages of the negative-ion mode would lead to counts that directly correlate to decreasing ambient pressure, but instead we measured an increase from about $50 \mathrm{kHz}$ in Fig. $7 \mathrm{~b}$ to about $100 \mathrm{kHz}$ in Fig. 7c.

In Fig. $7 \mathrm{~d}$ at $105.6 \mathrm{~km}$ altitude, increased levels of noise can be seen with no obvious small- or large-ion signatures. However, the largest spikes at $m / z$ 1688, $m / z$ 1245, $m / z 778$ and $m / z 308$ are $0.27 \mathrm{~s}$ apart and thus indicate some heavy ions again modulated by the rocket spin.

\subsection{Charge balance}

It is usually assumed that the atmosphere is quasineutral such that the positive-ion density balances the negative-ion and electron density: $N^{+}=N^{-}+N_{\mathrm{e}}$. At around $70 \mathrm{~km}$ we measured a maximum count rate of $26 \mathrm{kHz}$ for positive ions and around $300 \mathrm{kHz}$ for negative ions (light ions + heavy ions). Count rates may be converted to ion densities by the air column swept out through the intake orifice and rocket velocity: $N=c /\left(\pi r^{2} v\right)$. This leads to ion densities of $N^{+}=32 \mathrm{~cm}^{-3}$ and $N^{-}=379 \mathrm{~cm}^{-3}$. In Latteck et al. (2019) the electron density at $70 \mathrm{~km}$ was about $500 \mathrm{~cm}^{-3}$, suggesting about 27 times more negative charges than positive. At around $55 \mathrm{~km}$ the situation is even worse with very few positive counts. The simple conversion of counts to ion density above, does not consider effects such as the transmission efficiency of ions between intake and CEM; the absolute detection efficiency of the CEM and the payload potential, which might explain the imbalance of charges. The transmission efficiency of the quadrupole in RF-only mode is assumed to be close to unity (Schulte and Arnold, 1992) and should be equal for both charge states as the potential amplitudes are identical between the positive- and negative-ion mode. The absolute detection efficiency across the mass range of our instrument for the $\mathrm{MgO}$-coated CEM is presently unknown. For the same CEM model but without $\mathrm{MgO}$ coating and similar ion energies, Keller and Cooper (1996) found the absolute detection efficiency for oxygen to be about 0.6 for positive ions and 
0.7 for negative ions. Heavier atomic ions generally have a lower detection efficiency (Krems et al., 2005), e.g. xenon with 0.15 at $2 \mathrm{keV}$, but publications are scarce for heavier molecules. Measurements from Gilmore and Seah (2000) on microchannel plates indicate a rather low detection efficiency of around 0.02 for molecules of $2352 \mathrm{u}$ at $2 \mathrm{keV}$. A positive payload potential and therefore a positive potential on our intake cone could decrease positive-ion count rates and increase negative-ion count rates. Such a potential is the result of currents to and from the payload interacting with the surrounding plasma, mainly dominated by free electrons (Darian et al., 2017; Friedrich et al., 2013; Sternovsky et al., 2004). At $70 \mathrm{~km}$ and below, the electron density is low and the presence of heavy negative ions as carriers of negative charges could eventually lead to a positive payload potential as they are much slower than free electrons and the dominating positive ions. However, other effects such as photoemission or triboelectric charging (Havnes and Næsheim, 2007; Antonsen et al., 2019) could lead to positive charging. In the D-region, payload charging has been known as a major error source for quantitative rocket-borne measurements for a long time (Thrane, 1986). Hence, the effect of payload charging on the presented observations, with its apparent departure from charge neutrality, needs to be investigated in more detail. A full treatment of payload charging effects is beyond the scope of this investigation and will be dealt with in detail in a future publication.

\section{Conclusions}

With ROMARA, we successfully re-vitalized an instrument concept to make mass spectrometric measurements in the mesosphere and lower thermosphere. With its extended mass range for MSPs, ROMARA detects ambient atmospheric positive and negative ions up to $m / z 2000$ and in addition measures the total count rate of ions with masses above $m / z$ 2000. We have simulated the instrument's aerodynamic and ion-optical behaviour and conducted laboratory measurements for the characterization of ROMARA. The first ROMARA flight, which took place at noon on 13 April 2018 and reached an apogee of $121.4 \mathrm{~km}$, was successful in detecting ambient atmospheric positive and large negative ions. After the flight the instrument was recovered nearly undamaged. Six exemplary mass spectra of ambient atmospheric positive and negative ions, measured during rocket ascent, are shown in the present paper and demonstrate the successful application of an instrument to conditions in the middle atmosphere.

The most important scientific results of the ROMARA data presented here concern the detection of large negative ions and a strong indication for the absence of large positive ions. Most likely, the large ions are actually negatively charged meteor smoke particles with radii of about 0.6 to $2.5 \mathrm{~nm}\left(\mathrm{~m} / z 2000-m / z 10^{5}\right)$. Besides large negative ions, small negative ions with masses mostly below $m / z$. 150 were also detected at $70 \mathrm{~km}$. At $106 \mathrm{~km}$, no negative ions were detected. These findings are consistent with previous measurements. Positive ions measured at $70 \mathrm{~km}$ are mostly hydrated cluster ions up to $m / z 73$. At $106 \mathrm{~km}$ the detected small positive ions have mass numbers around $m / z$ 30. Again, this is consistent with previous measurements that found $\mathrm{H}^{+}\left(\mathrm{H}_{2} \mathrm{O}\right)_{3}[55 \mathrm{u}]$ and $\mathrm{H}^{+}\left(\mathrm{H}_{2} \mathrm{O}\right)_{4}[73 \mathrm{u}]$ to dominate at $70 \mathrm{~km}$ and $\mathrm{NO}^{+}[30 \mathrm{u}]$ and $\mathrm{O}_{2}^{+}[32 \mathrm{u}]$ to dominate at $105 \mathrm{~km}$. Large positive ions were not detected at 70 nor at $105 \mathrm{~km}$ above our measurement threshold. From our large-ion measurements at $70 \mathrm{~km}$ the following conclusions may be drawn. The presence of large negative ions suggests that at $70 \mathrm{~km}$ electron attachment to neutral MSPs was sufficiently fast and neutralization of negative MSPs by photodetachment and recombination with positive ions was sufficiently slow to allow a substantial fraction of MSPs to be negatively charged. The absence of positive MSPs suggests that neutralization of positive MSPs by collisions with free electrons was faster than positive MSP formation by uptake of positive ions.

Data availability. The data is available through the HALO database: https://halo-db.pa.op.dlr.de/ongoing_subset/1207 (Stude, 2020).

Author contributions. JS was responsible for the following: investigation, methodology, formal analysis, project administration, software, visualization, and writing of the original draft;

HA for the investigation, validation, software, and writing (review and editing); HS for supervision and writing (review and editing); MR for funding acquisition, supervision, and writing (review and editing); FA for conceptualization, validation, supervision, and writing (review and editing); an BS for conceptualization, and writing (review and editing).

Competing interests. The authors declare that they have no conflict of interest.

Acknowledgements. The authors wish to express their thanks to the mobile rocket base (MORABA) and Andøya Space Center (ASC) for their intense support and help. We would also like to thank Bernhard Preissler $(\dagger)$, Robert Lindemann and Systemhaus Technik for their dedicated technical support. We further acknowledge discussions at working groups 414 and 437 at the International Space Science Institute (ISSI) in Bern, Switzerland.

Financial support. Project PMWE was funded by the German Federal Ministry for Economic Affairs and Energy and by the German Aerospace Center (DLR) (grant no. 50OE1402). 
Review statement. This paper was edited by Troy Thornberry and reviewed by two anonymous referees.

\section{References}

Antonsen, T., Havnes, O., and Spicher, A.: Multi-scale measurements of mesospheric aerosols and electrons during the MAXIDUSTY campaign, Atmos. Meas. Tech., 12, 2139-2153, https://doi.org/10.5194/amt-12-2139-2019, 2019.

Arnold, F. and Fabian, R.: First measurements of gas phase sulphuric acid in the stratosphere, Nature, 283, 55-57, https://doi.org/10.1038/283055a0, 1980.

Arnold, F. and Knop, G.: Stratospheric nitric acid vapour measurements in the cold Arctic vortex: implications for nitric acid condensation, Nature, 338, 746-749, https://doi.org/10.1038/338746a0, 1989.

Arnold, F., Kissel, J., Krankowsky, D., Wieder, H., and Zähringer, J.: Negative ions in the lower ionosphere: A mass-spectrometric measurement, J. Atmos. Sol.-Terr. Phy., 33, 1169-1175, https://doi.org/10.1016/0021-9169(71)90104-8, 1971.

Arnold, F., Krankowsky, D., and Marien, K.: First mass spectrometric measurements of positive ions in the stratosphere, Nature, 267, 30-32, https://doi.org/10.1038/267030a0, 1977a.

Arnold, F., Krankowsky, D., Marien, K., and Joos, W.: A mass spectrometer probe for composition and structure analysis of the middle atmosphere plasma and neutral gas, edited by: Dieminger, W. and Untiedt, J., J. Geophys.-Z. Geophys., 44, 125-138, https://doi.org/10.23689/fidgeo-3161, 1977b

Arnold, F., Fabian, R., and Joos, W.: Measurements of the height variation of sulfuric acid vapor concentrations in the stratosphere, Geophys. Res. Lett., 8, 293-296, https://doi.org/10.1029/GL008i003p00293, 1981.

Arnold, F., Viggiano, A., and Ferguson, E.: Combined mass spectrometric composition measurements of positive and negative ions in the lower ionosphere - II, Negative ions, Planet. Space Sci., 30, 1307-1314, https://doi.org/10.1016/0032-0633(82)90104-0, 1982.

Arnold, F., Schlager, H., Hoffmann, J., Metzinger, P., and Spreng, S.: Evidence for stratospheric nitric acid condensation from balloon and rocket measurements in the Arctic, Nature, 342, 493497, https://doi.org/10.1038/342493a0, 1989.

Asmus, H., Staszak, T., Strelnikov, B., Lübken, F.-J., Friedrich, M., and Rapp, M.: Estimate of size distribution of charged MSP's measured in situ in winter during the WADIS-2 sounding rocket campaign, Ann. Geophys., 35, 979-998, https://doi.org/10.5194/angeo-35-979-2017, 2017.

Bacher, G., Szymanski, W. W., Kaufman, S. L., Zöllner, P., Blaas, D., and Allmaier, G.: Charge-reduced nano electrospray ionization combined with differential mobility analysis of peptides, proteins, glycoproteins, noncovalent protein complexes and viruses, J. Mass Spectrom., 36, 1038-1052, https://doi.org/10.1002/jms.208, 2001.

Bird, G.: Aerodynamic effects on atmospheric composition measurements from rocket vehicles in the thermosphere, Planet. Space Sci., 36, 921-926, https://doi.org/10.1016/00320633(88)90099-2, 1988.

Bird, G.: Molecular Gas Dynamics and the Direct Simulation of Gas Flows, Oxford University Press, New York, 1994.
Britt, D. T. and Consolmagno, G. J. S. J.: Stony meteorite porosities and densities: A review of the data through 2001, Meteorit. Planet. Sci., 38, 1161-1180, https://doi.org/10.1111/j.19455100.2003.tb00305.x, 2003.

Brubaker, W.: An improved quadrupole mass analyzer, Adv. Mass. Spect., 4, 293-299, 1968.

Crutzen, P. J. and Arnold, F.: Nitric acid cloud formation in the cold Antarctic stratosphere: a major cause for the springtime "ozone hole", Nature, 324, 651-655, https://doi.org/10.1038/324651a0, 1986.

Curtius, J., Weigel, R., Vössing, H.-J., Wernli, H., Werner, A., Volk, C.-M., Konopka, P., Krebsbach, M., Schiller, C., Roiger, A., Schlager, H., Dreiling, V., and Borrmann, S.: Observations of meteoric material and implications for aerosol nucleation in the winter Arctic lower stratosphere derived from in situ particle measurements, Atmos. Chem. Phys., 5, 3053-3069, https://doi.org/10.5194/acp-5-3053-2005, 2005.

Dahl, D. A.: SIMION for the personal computer in reflection, Int. J. Mass Spectrom., 200, 3-25, https://doi.org/10.1016/S13873806(00)00305-5, 2000.

Darian, D., Marholm, S., Paulsson, J. J. P., Miyake, Y., Usui, H., Mortensen, M., and Miloch, W. J.: Numerical simulations of a sounding rocket in ionospheric plasma: Effects of magnetic field on the wake formation and rocket potential, J. Geophys. Res.Space, 122, 9603-9621, https://doi.org/10.1002/2017JA024284, 2017.

Douglas, D.: Linear quadrupoles in mass spectrometry, Mass Spectrom. Rev., 28, 937-960, https://doi.org/10.1002/mas.20249, 2009.

Fentzke, J. T., Janches, D., Strelnikova, I., and Rapp, M.: Meteoric smoke particle properties derived using dual-beam Arecibo UHF observations of D-region spectra during different seasons, J. Atmos. Sol.-Terr. Phy., 71, 1982-1991, https://doi.org/10.1016/j.jastp.2009.09.002, 2009.

Fentzke, J. T., Hsu, V., Brum, C. G. M., Strelnikova, I., Rapp, M., and Nicolls, M.: D-region meteoric smoke and neutral temperature retrieval using the Poker Flat incoherent scatter radar, Geophys. Res. Lett., 39, L21102, https://doi.org/10.1029/2012GL053841, 2012.

Frankland, V. L., James, A. D., Feng, W., and Plane, J. M.: The uptake of $\mathrm{HNO}_{3}$ on meteoric smoke analogues, J. Atmos. Sol.-Terr Phy., 127, 150-160, https://doi.org/10.1016/j.jastp.2015.01.010, 2015.

Friedrich, M., Rapp, M., Blix, T., Hoppe, U.-P., Torkar, K., Robertson, S., Dickson, S., and Lynch, K.: Electron loss and meteoric dust in the mesosphere, Ann. Geophys., 30, 1495-1501, https://doi.org/10.5194/angeo-30-1495-2012, 2012.

Friedrich, M., Torkar, K. M., Hoppe, U.-P., Bekkeng, T.-A., Barjatya, A., and Rapp, M.: Multi-instrument comparisons of Dregion plasma measurements, Ann. Geophys., 31, 135-144, https://doi.org/10.5194/angeo-31-135-2013, 2013.

Gelinas, L. J., Lynch, K. A., Kelley, M. C., Collins, S., Baker, S., Zhou, Q., and Friedman, J. S.: First observation of meteoritic charged dust in the tropical mesosphere, Geophys. Res. Lett., 25, 4047-4050, https://doi.org/10.1029/1998GL900089, 1998.

Gilmore, I. and Seah, M.: Ion detection efficiency in SIMS: Dependencies on energy, mass and composition for microchannel plates used in mass spectrometry, Int. J. Mass Spectrom., 202, 217-229, https://doi.org/10.1016/S1387-3806(00)00245-1, 2000. 
Havnes, O. and Næsheim, L. I.: On the secondary charging effects and structure of mesospheric dust particles impacting on rocket probes, Ann. Geophys., 25, 623-637, https://doi.org/10.5194/angeo-25-623-2007, 2007.

Havnes, O., Antonsen, T., Hartquist, T., Fredriksen, A., and Plane, J.: The Troms $\varnothing$ programme of in situ and sample return studies of mesospheric nanoparticles, J. Atmos. Sol.-Terr. Phy., 127, 129136, https://doi.org/10.1016/j.jastp.2014.09.010, 2015.

Hedin, J., Gumbel, J., and Rapp, M.: On the efficiency of rocketborne particle detection in the mesosphere, Atmos. Chem. Phys., 7, 3701-3711, https://doi.org/10.5194/acp-7-3701-2007, 2007.

Hervig, M. E., Gordley, L. L., Deaver, L. E., Siskind, D. E., Stevens, M. H., Russell III, J. M., Bailey, S. M., Megner, L., and Bardeen, C. G.: First Satellite Observations of Meteoric Smoke in the Middle Atmosphere, Geophys. Res. Lett., 36, L18805, https://doi.org/10.1029/2009GL039737, 2009.

Hervig, M. E., Bardeen, C. G., Siskind, D. E., Mills, M. J., and Stockwell, R.: Meteoric smoke and $\mathrm{H}_{2} \mathrm{SO}_{4}$ aerosols in the upper stratosphere and mesosphere, Geophys. Res. Lett., 44, 11501157, https://doi.org/10.1002/2016GL072049, 2017.

Hunten, D. M., Turco, R. P., and Toon, O. B.: Smoke and Dust Particles of Meteoric Origin in the Mesosphere and Stratosphere, J. Atmos. Sci., 37, 1342-1357, https://doi.org/10.1175/15200469(1980)037<1342:SADPOM>2.0.CO;2, 1980.

James, A. D., Brooke, J. S. A., Mangan, T. P., Whale, T. F., Plane, J. M. C., and Murray, B. J.: Nucleation of nitric acid hydrates in polar stratospheric clouds by meteoric material, Atmos. Chem. Phys., 18, 4519-4531, https://doi.org/10.5194/acp18-4519-2018, 2018.

Kalashnikova, O., Horányi, M., Thomas, G. E., and Toon, O. B.: Meteoric smoke production in the atmosphere, Geophys. Res. Lett., 27, 3293-3296, https://doi.org/10.1029/1999GL011338, 2000.

Keller, C. A. and Cooper, B. H.: Quantitative detection of low energy positive and negative ions with a channel electron multiplier, Rev. Sci. Instrum., 67, 2760-2764, https://doi.org/10.1063/1.1147104, 1996.

Kopp, E.: Positive and negative ions of the middle atmosphere, Adv. Space Res., 12, 325-333, https://doi.org/10.1016/02731177(92)90488-J, 1992.

Kopp, E., Ramseyer, H., and Björn, L.: Positive ion composition and electron density in a combined auroral and NLC event, Adv. Space Res., 4, 157-161, https://doi.org/10.1016/02731177(84)90279-5, 1984.

Krankowsky, D., Arnold, F., Wieder, H., and Kissel, J.: The elemental and isotopic abundance of metallic ions in the lower E-region as measured by a cryogenically pumped quadrupole mass spectrometer, Int. J. Mass Spectrom., 8, 379-390, https://doi.org/10.1016/0020-7381(72)83024-9, 1972.

Krems, M., Zirbel, J., Thomason, M., and DuBois, R. D.: Channel electron multiplier and channelplate efficiencies for detecting positive ions, Rev. Sci. Instrum., 76, 093305, https://doi.org/10.1063/1.2052052, 2005.

La Hoz, C. and Havnes, O.: Artificial modification of polar mesospheric winter echoes with an RF heater: Do charged dust particles play an active role?, (1984-2012), J. Geophys. Res.-Atmos., 113, D19205, https://doi.org/10.1029/2008JD010460, 2008.

Latteck, R., Singer, W., Rapp, M., Vandepeer, B., Renkwitz, T., Zecha, M., and Stober, G.: MAARSY: The new MST radar on Andøya-System description and first results, Radio Sci., 47, RS1006, https://doi.org/10.1029/2011RS004775, 2012.

Latteck, R., Renkwitz, T., and Strelnikov, B.: D region observations by VHF and HF radars during a rocket campaign at Andøya dedicated to investigations of PMWE, Adv. Radio Sci., 17, 225-237, https://doi.org/10.5194/ars-17-225-2019, 2019.

Lynch, K. A., Gelinas, L. J., Kelley, M. C., Collins, R. L., Widholm, M., Rau, D., MacDonald, E., Liu, Y., Ulwick, J., and Mace, P.: Multiple sounding rocket observations of charged dust in the polar winter mesosphere, J. Geophys. Res.-Space, 110, A03302, https://doi.org/10.1029/2004JA010502, 2005.

Plane, J. M. C.: Atmospheric Chemistry of Meteoric Metals, Chem. Rev., 103, 4963-4984, https://doi.org/10.1021/cr0205309, 2003.

Plane, J. M. C.: Cosmic dust in the earth's atmosphere, Chem. Soc. Rev., 41, 6507-6518, https://doi.org/10.1039/C2CS35132C, 2012.

Plane, J. M. C., Saunders, R. W., Hedin, J., Stegman, J., Khaplanov, M., Gumbel, J., Lynch, K. A., Bracikowski, P. J., Gelinas, L. J., Friedrich, M., Blindheim, S., Gausa, M., and Williams, B. P.: A combined rocket-borne and groundbased study of the sodium layer and charged dust in the upper mesosphere, J. Atmos. Sol.-Terr. Phy., 118, 151-160, https://doi.org/10.1016/j.jastp.2013.11.008, 2014.

Rapp, M. and Lübken, F.-J.: Modelling of particle charging in the polar summer mesosphere: Part 1 - General results, J. Atmos. Sol.-Terr. Phy., 63, 759-770, https://doi.org/10.1016/S13646826(01)00006-2, 2001.

Rapp, M. and Thomas, G. E.: Modeling the microphysics of mesospheric ice particles: Assessment of current capabilities and basic sensitivities, J. Atmos. Sol.-Terr. Phy., 68, 715-744, https://doi.org/10.1016/j.jastp.2005.10.015, 2006.

Rapp, M., Hedin, J., Strelnikova, I., Friedrich, M., Gumbel, J., and Lübken, F.-J.: Observations of positively charged nanoparticles in the nighttime polar mesosphere, Geophys. Res. Lett., 32, L23821, https://doi.org/10.1029/2005GL024676, 2005.

Rapp, M., Strelnikova, I., and Gumbel, J.: Meteoric smoke particles: Evidence from rocket and radar techniques, Adv. Space Res., 40, 809-817, https://doi.org/10.1016/j.asr.2006.11.021, 2007.

Rapp, M., Latteck, R., Stober, G., Hoffmann, P., Singer, W., and Zecha, M.: First three-dimensional observations of polar mesosphere winter echoes: Resolving spacetime ambiguity, J. Geophys. Res.-Space, 116, A11307, https://doi.org/10.1029/2011JA016858, 2011.

Rapp, M., Plane, J. M. C., Strelnikov, B., Stober, G., Ernst, S., Hedin, J., Friedrich, M., and Hoppe, U.-P.: In situ observations of meteor smoke particles (MSP) during the Geminids 2010: constraints on MSP size, work function and composition, Ann. Geophys., 30, 1661-1673, https://doi.org/10.5194/angeo30-1661-2012, 2012.

Robertson, S., Dickson, S., Horányi, M., Sternovsky, Z., Friedrich, M., Janches, D., Megner, L., and Williams, B.: Detection of meteoric smoke particles in the mesosphere by a rocket-borne mass spectrometer, J. Atmos. Sol.-Terr. Phy., 118, 161-179, https://doi.org/10.1016/j.jastp.2013.07.007, 2014.

Rosinski, J. and Snow, R. H.: Secondary particulate matter from meteor vapors, J. Meteorol., 18, 736-745, https://doi.org/10.1175/15200469(1961)018<0736:SPMFMV>2.0.CO;2, 1961. 
Schulte, P. and Arnold, F.: Detection of upper atmospheric negatively charged microclusters by a rocket-borne mass spectrometer, Geophys. Res. Lett., 19, 2297-2300, https://doi.org/10.1029/92GL02631, 1992.

Shipway, A. and Shipway, S.: CalcTool, available at: http: //www.calctool.org/CALC/prof/bio/protein_length (last access: 30 May 2018), 2008.

Staszak, T., Strelnikov, B., Latteck, R., Renkwitz, T., Friedrich, M., Baumgarten, G., and Lübken, F.-J.: Turbulence generated smallscale structures as PMWE formation mechanism: results from rocket campaign, J. Atmos. Sol.-Terr. Phy., submitted, 2021.

Sternovsky, Z., Holzworth, R. H., Horányi, M., and Robertson, S.: Potential distribution around sounding rockets in mesospheric layers with charged aerosol particles, Geophys. Res. Lett., 31, L22101, https://doi.org/10.1029/2004GL020949, 2004.

Strelnikov, B., Szewczyk, A., and Rapp, M.: In Situ Measurements of Small-Scale Structures in Neutrals and Charged Aerosols, in: Aeronomy of the Earth's Atmosphere and Ionosphere, Springer, the Netherlands, 83-91, https://doi.org/10.1007/97894-007-0326-1, 2012.

Strelnikov, B., Staszak, T., Latteck, R., Renkwitz, T., Strelnikova, I., Lübken, F.-J., Baumgarten, G., Chau, J. L., Stude, J., Rapp, M., Hörner, I., Löhle, S., Eberhart, M., Fasoulas, S., Friedrich, M., Gumbel, J., Hedin, J., Hörschgen-Eggers, M., Giono, G., and Belova, E.: Sounding rocket project PMWE for investigation of polar mesosphere winter echoes, J. Atmos. Sol.-Terr. Phy., submitted , 2021.
Strelnikova, I., Rapp, M., Raizada, S., and Sulzer, M.: Meteor smoke particle properties derived from Arecibo incoherent scatter radar observations, Geophys. Res. Lett., 34, L15815, https://doi.org/10.1029/2007GL030635, 2007.

Stude, J.: FLIGHT: 180413A (ROMARA_PMWE1F_HDB), available at: https://halo-db.pa.op.dlr.de/ongoing_subset/1207, last access: 16 November 2020.

Thrane, E. V.: Middle Atmosphere Program, ICSU Scientific Committee on Solar-Terrestrial Physics, vol. 19, chap. 6, available at: https://books.google.de/books?id=b8MfAAAAIAAJ\& $\mathrm{dq}=$ MiddleAtmosphereProgramvol019thrane\&pg=PP6\#v= onepage $\& \mathrm{q}=$ MiddleAtmosphereProgramvol19thrane $\& \mathrm{f}=$ false (last access: 2 February 2020), 138-154, 1986.

Voigt, C., Schlager, H., Luo, B. P., Dörnbrack, A., Roiger, A., Stock, P., Curtius, J., Vössing, H., Borrmann, S., Davies, S., Konopka, P., Schiller, C., Shur, G., and Peter, T.: Nitric Acid Trihydrate (NAT) formation at low NAT supersaturation in Polar Stratospheric Clouds (PSCs), Atmos. Chem. Phys., 5, 13711380, https://doi.org/10.5194/acp-5-1371-2005, 2005 